\title{
Web Based and Online Applications in STEM Education
}

\author{
https://doi.org/10.3991/ijep.v9i4.10691 \\ Chrysovalantis Kefalis $\left.{ }^{\bowtie}\right)$, Athanasios Drigas \\ N.C.S.R. 'Demokritos', Athens, Greece \\ vkefalis@iit.demokritos.gr
}

\begin{abstract}
STEM is an educational approach to the integration of science, mathematics, engineering and technology which are taught as nunnery through real life-inspired activities. In this paper we present the latest trends in webbased and online STEM education. By exploiting connectivity, increasing the means that can be shared online and developing cooperation between people from distance, new educational paradigms are immerging. We chose to present applications from 2013 onwards in order to highlight the latest trends in STEM online education and have categorize them according the technologies used in their implementation.
\end{abstract}

Keywords-STEM, virtual labs, web 2.0, science education, web-based learning, distance learning, ICT, online education.

\section{Introduction}

STEM stands for science, mathematics, engineering and technology, it is based on the idea that these four fields should not be seen separately. It is an educational approach to the integration of these four fields of knowledge, which are taught as nunnery through real life-inspired activities. It is worth noting the fact that in recent years there has been a great debate on the possibility of incorporating Arts and the evolution from STEM to STEAM. [1] By no doubt advances in STEM related fields have made significant contributions to the world and STEM-related jobs are in growth the last couple of years.[2]

'Advances in STEM have already brought about improvements in many aspects of life, such as health, agriculture, infrastructure and renewable energy. STEM education is also key for preparing students for the world of work, enabling entry into indemand STEM careers of tomorrow.'

UNESCO 2017. P.14 [3]

In addition, the complicated new world and modern problems in fields that demand by individuals and societies high level of science and technological literacy (agricultural production, greenhouse effect, genetic modification etc.), makes STEM education a high priority. The skills acquired by STEM education even referred by World Economic Forum as a measurement of the future preparedness of the countries [4].

The role of ICTs (Information and Communication Technologies) in education, and its application in various fields, is a topic that has been extensively discussed in 
the literature [5], [6],[7]. The impact of the use of new technologies on education has begun to be studied since the 1970s. At that time, both trainers and governments began to be persuaded that incorporating these technologies could support students in formal education [8].

The advent of the internet in the 90s radically changed education. The telecommunications revolution makes information sharing much easier and faster. The economy is changing and that change affected education to, new pedagogical models immerge at all levels of education [9].

Today's students are very different from previous generations. They have grown up in an environment so much different that they have even been called the generation that have been 'born digital' [10]. Web based applications promote learning in many ways since are close to pupils' needs and interests. Web based applications are easy to access from everywhere, are easy to use and gives the opportunity to pupils to learn in an authentic way through real life-inspired activities. In this paper we focus on online applications in stem-related fields. In an effort to explore more closely how the internet has affected education in stem-related fields we search the literature for applications that exploit the web not only just as an information search tool but as a tool that plays central role in the educational process. We chose to present applications from 2013 onwards so as to highlight the latest trends in STEM online education and have categorize them according the technologies used in their implementation.

\section{Distance Learning}

Choi \& Walters in an effort to identify effective supports for online students, examined the impact of synchronous discourse sessions of small groups on fully online learning environments on mathematics. Students of two virtual elementary schools participated in the pilot program, a total of 898 pupils. The results showed that pupils that had participated in more synchronous sessions scored higher in their exams. On the other hand, there was no difference as far as the confidence, self-efficacy and mindset of students is concerned.[11]

Choi, Walters, \& Hoge in order to evaluate the way self-reflection supports math learning in an online learning environment of eight virtual schools in the United States, conducted three studies with a total of 2,250 pupils from all levels of education. According to their results middle school students showed the strongest association between their reflection participation, reflected confidence, and actual performance level, especially in more easy math tasks. [12]

Hong et al. investigated the learner- learner interaction of a massive open online course (MOOC). The provider of this chemistry course was coursera. They have used interaction analysis model (IAM) in order to conceptualize learner-learner interactions. Their analysis relied on writings of all online discussions during the course. A total of 274 students and three instructors were involved with the lesson. Their findings suggest that learners did not engage in high degrees of co-construction of knowledge, their posts were focused on stating opinions or answering and asking questions.[13] 
Robinson et al. investigated the use of MOOC in geography teaching. They used ArcGIS online web mapping tools to design mapping assignments, video presentations and short video lectures for the lesson content. For the assessment of students' performance weekly multiple-choice quizzes, discussion participation, a peerevaluated map design project, and a cumulative final exam were used[14].

Rennar-Potacco \& Orellana conducted a mixed method study in order to identify the important factors to consider when designing an online academic support program (OLASP) through videoconferencing to students in Science, Technology, Engineering, and Mathematics (STEM) courses. According to their results online academic support can help reduce the socioeconomic gap, mitigate the academic unpreparedness that contributes to the low retention rates of students in STEM courses, and meet the academic support needs of students with divergent needs[15].

Sun \& Looi developed WiMVT (web-based inquirer with modelling and visualization technology), a MbSLE (model-based science learning environment) system designed to help secondary school students on science courses. The system is designed to enable teachers and students to create, organize and share their own material through extensible client server architecture. They evaluated a simplified version of the system through a pilot study which included 46 secondary school students in Singapore. As the results of their pilot study suggest the system could have a positive impact on students' conceptual understanding, collaboration, modeling skills and selfreflective skills in science learning[16].

\section{Online Virtual Lab}

Silva et al. introduced a 'Dc electric panel' remote lab, which aims to help high school and higher education students in basic electronics. Resistors, Led, switches and a power supply were used to make the dc panel. Depending on which switches the user activates deferent circuit occurs. For measurements multimeters were used as voltmeters or ammeters. They used Raspberry $\mathrm{Pi} \mathrm{B}+$ which provided interfacing and management for the connections between the web and "Acquisition and Control Board" and other hardware devices via UART (Universal Asynchronous Receiver / Transmitter) that communicates via MODBUS2 protocol. As virtual learning environment Moodle is used for the students to access the educational content[17].

Darrah et. al. tested the effectiveness of virtual labs in comparison with hands-on labs in physics in two major Universities. The participants were 224 students from both universities. In the first group students used virtual labs as alternatives to traditional ones, or as tools to support them, the second group of students used hands-on labs and played the role of the control group. In each one of the Virtual Labs everything that a student would need was included: objectives, background theory, 3D simulation, brief video, data collection tools. Pre and postlab question were also included to both groups, in order to evaluate the intervention. As far as the effectiveness of both methods regards, the results of the study suggest that there is no difference. Virtual labs are as much effective as traditional labs in science education. As they point out, virtual-labs reduce equipment needs, are available at anytime from any- 
where, offer more information to students and offer students the opportunity to work at their own pace while exploring difficult or interesting concepts[16]).

A study for the impact of a remote lab in engineering higher education conducted by Viegas et al. in Brazil. 471 students took part in the study, nearly half of them where studding engineer topics and the other half were students of other majors. The students' results of the study where cross analysed with the course characteristics in order to identify some patterns in factors that might influence student results. As shown by the survey data the virtual lab was more useful in basic courses than advanced ones. The biggest advantage of the virtual lab, as shown by the students' answers, was the accessibility anytime and everywhere. This allowed students to do their work at their own pace. Another interesting point that the data reveal is that the students which benefit most of the virtual lab were the students with more learning needs [19].

Robinson et. al. has developed a remote lab environment designed for use in sessions for robotic tasks. The lab consists of two robotic arms, an IP camera, an Arduino card and network access routers to connect the remote site with the physical lab. Denavit-Hartenberg (D-H) algorithm was used, in order to use geometric parameters of the robots to determine the position and orientation of the end effector of the robot. A web interface in the virtual environment was used to allow users to manipulate each degree of freedom. The servomotors of each robotic arm were connected with Andruino control board and an ethernet connectivity card was used in order to connect the board with the router on the physical laboratory. To evaluate the remote working environment a series of tasks were performed by 5 users who were previously trained in the manipulation of the different degrees of freedom. As the results of the study show all users managed to perform the tasks with a precision of $80 \%$ [18].

Vijayan et al., in order to provide affordable laboratory education, implemented a remote lab for engineering education using two deferent approaches. In the first application commercial software and hardware was used, National Instruments Lab-VIEW, data acquisition cards and XML- based input. On the second approach they have used Free and Open Source Software (FOSS), Raspberry Pi as controller and a JAVAbased web server for communication purposes. Adaptive Exponential Integrate and Fire (AdEx) models were used to represent spiking neurons and the network adapts the Cerebellar Motor Articulation Control (CMAC). According to their research results the remote laboratory motivated self-organized learning to students and proved to be very useful as teaching material to teachers[21].

\section{Web 2.0}

Gokhale et al. in order to create a real-world example for STEM education in high school, they have created C2SuMo, a cloud-hosted simulation-as-a-service. They combined google map interface with Sumo traffic simulator in order to hide from the students the simulator complexity. Ubiquitous access was achieved also by this combination as the app is available via browsers, and all different traffic patterns are conducted through web-based and mobile-based user interfaces available through a cli- 
ent-side web browser. The backend of SUMO simulation was hosted in the Apache web server and CherryPy web framework. Virtual Machines in the cloud were used for the actual execution of the simulation and TraCI protocol allows the system to make modifications on the objects' behaviour in real time. They also used a modified Python-based TraCI client to be possible for the web server to connect multiple incoming user request to their own SUMO server and MongoDB as a database for persisting media files and documents as well as applications' configuration such as user groups. Google hangouts was integrated so the framework is useful in both individual and collaboration mode. The framework was tested among 64 high school students and there was improvement in stem topics but not in CT assessments [22].

Lin et al. developed a web-based assessment system for evaluating junior high students' collaborative problem-solving skills (CPS) in the context of STEM education. The students had to work together with a computer avatar to solve problems from their everyday life. Through the keyboard students were communicate with the avatar for guidance or to ask for several items. The Avatar was searching in an item bank and responded to their request. Their system has been tested among 222 junior high students and the result suggest that the assessment system was effective in assessing students' collaborative problem-solving skills [23].

Lin et. al. has investigated the integration of Facebook discussion combined with simulation tools in teaching network troubleshooting. During their research 45 college students took a 16 week «Introduction to the Network» course. Pre and post-test were used in order to evaluate network troubleshooting abilities. As the results suggest there was a significant difference before and after the learning activity in learners network troubleshooting abilities. The data about cognitive processing behaviours were coded based on the content of their Facebook group discussions showed that the highest proportion of Facebook discussion was about cognitive processes understand and analyse rather than apply and remember [24].

Kobayashi et al. designed a blended educational activity about nuclear safety using Metaverse (Second Life). The activity was designed to be implemented in elementary school children (11 and 12 years old). Pupils' computer and internet literacy, at that age, is still at an early stage, so to overcome that problem they combined the virtual class with hands-on activities. As the results of their pilot research showed Metaverse can be very effective in a blended educational activity, in both educational and emotional objectives [25].

\section{$5 \quad$ Online Tools}

Segeč, Kubina, \& Palúch developed ViRo, an online tool that allows students remote access to predefined network topologies running on an emulation server. Their tool was built on GNU/Linux operating system. The core of the application consists of Dynamips simulation to provide the virtual device emulator and Dynagen extension to facilitate startup of topologies. A web interface is used for the communication of the user with the system. MySQL database system is used to store the data used by web interface and by emulator application. A Java Telnet Application accessible directly 
from the internet is used for communication with individual virtual devices and lastly a community portal extension was embedded in order to allow the sharing and the distribution of knowledge. For the development of the tool PHP was used and Drupal Content Management System (CMS) as the framework of the final solution[26].

$\mathrm{Ng}$, investigated the design and impact of a school- university- industry designed online module on climate science. From this collaboration E $\Delta$ RTH e-Module was the product, an integrated STEM module that promoted climate science literacy. The emodule was made up of four units where within each unit, there were several lessons. Simulations were also embedded on the e-Module's activities. As for monitoring and assessment of the student's performance the learning platform for E $\Delta \mathrm{RTH}$ had learning analytics capabilities. The results of the study suggest that engaging teachers in the design of the e-module that they will use in their classroom produced positive attitudes towards the use of the materials with their students. As far as the students' performance is concerned most of the teachers found that their students had a better understanding of the scientific processes [27].

Clevenger et. al. used online tools to promote learning of sustainability principles in construction engineering education. They compared Autodesk BPA and Procore, two free online training courses on two related sustainability aptitudes: (1) systems thinking and understanding of interconnectedness, and (2) action-orientation and change-agent skills. The authors conducted a study by paper and online surveys to students enrolled in two graduate-level courses offered as part of a construction engineering and management master program. their findings suggest that BPA is very effective in promoting the skills required [28].

Hostovecky et. al. developed a software to detect key knowledge and skills of students in primary and secondary schools in Slovakia and the Czech Republic. Pupils filled testing tasks through the internet, so assessment and analyses of the results was faster and immediately processed. As the results of the study indicate web-based testing is very useful for collecting data but it can be a very effective tool to increase digital literacy for students and teachers as well [29].

\section{Online Games}

Fellnhofer conducted a research in order to evaluate an online math game and to broaden the specific features of an educational game that are important to its success. Their sample consisted of 65 Austrian students aged between 10 and 20 years old and a control group of 41 players. They have measured game success, indicators of enjoyment and indicators of flow. Their results suggest that game elements support game's success, gender and age do not have any influence and educational topic must be taken into account when designing a math game [30].

Jagoda et al. designed and tested The Source, an alternate reality game (ARG) developed by the Game Changer Chicago (GCC) Design Lab. A game premeditated to foster interest and knowledge related to science, technology, engineering, and math (STEM) among youth from populations underrepresented in STEM fields. The activities included, among others, online games about technology and hacking, blogging 
about STEM topics, board games about maths and cryptography. Through multiplayer and social emphasis design small teams were formed for collaboration. A total of 144 participants took part in a five-week summer program, 43 of them participated in the evaluation process which contained interviews followed by qualitative analysis. According to their results game-based learning can promote collaboration, narrative and games can be used to show STEM' relation to the real world, peer to peer mentoring sparkles STEM' interest of the youth and finally the results pointed out the importance of collective role playing in education [31].

Mavridis, Katmada, \& Tsiatsos used an online flexible game in mathematics. At their study participated 79 students and 4 teachers of a public secondary school. Half of them were the control group and the other half the experimental one. A pre and a post questionnaire was used in order to identify students' attitude to mathematics, two equivalent paper-based tests was used to evaluate the before and after the intervention knowledge and finally a series of semi-constructed interviews were carried out with a view to validating the results of the questionnaires. The statistical analysis of the data was conducted using ANCOVA and MANCOVA tests. As the results of their study suggest the game had a positive effect on students' attitudes on the value, enjoyment and motivation dimensions and there was no gender difference of the results [32].

Hursen \& Bas conducted a research for the impact of the use of gamification applications in science education. They have used a virtual class via ClassDojo, an application which allows users to share photographs, videos and messages online in order to work as a team and share the classroom experience. In their study conducted in 16 pupils of 4th grade, a significant increase between the scores obtained from the motivation scale for learning science before the and after application was obtained. Their findings also suggest that students were satisfied with gamification applications [33].

\section{Conclusion}

In this review, we tried to present the latest trends in STEM education that exploit the web not only just as an information search tool but as a tool that plays central role in the educational process. By exploiting connectivity, increasing the means that can be shared online and developing cooperation between people from distance, new educational paradigms are immerging. People can access knowledge through distance in formal or even in the informal environment of moocs. With Web 2.0 tools the communication between learners and teachers is being synchronous and promotes collaboration. Virtual labs are made so flexible and easy to use and achieve the same cognitive results as real ones, saving both resources and time. Online tools help both teachers and learners access knowledge easy and effective promoting digital literacy and finally online games encourages and motivates students helping them learn in a playful way. Although the positive contribution of web based learning is widely accepted, more research needs to be done on how this know-how can go into more advanced areas of STEM related topics. 


\section{References}

[1] A.M. Connor, S. Karmokar, and C. Whittington, "From STEM to STEAM: Strategies for Enhancing Engineering \& Technology Education," International Journal of Engineering Pedagogy (iJEP), vol. 5, no. 2, p. 37, 2015. https://doi.org/10.3991/ijep.v5i2.4458

[2] M. J. Timms, K. Moyle, P. R. Weldon, and P. Mitchell, "Challenges in STEM learning in Australian schools: Literature and policy review," no. 7, 2018.

[3] UNESCO, "Cracking the code: Girls' and women's education in science, technology, engineering and mathematics (STEM)," UNESCO, 2017.

[4] R. Sheffield et al., "Transnational Examination of STEM Education," International Journal of Innovation in Science and Mathematics Education, vol. 26, no. 8, pp. 67-80, 2018.

[5] A. Khatri, S. Bansal, and A. K. Sinha, ICT, education and development: A review, vol. 68. 2015.

[6] N. Anyaegbunam and F. Anyaegbunam, Exploring the Role of ICT in Science Education., vol. 2007. Pp26. 2007.

[7] A. Drigas and R.-E. Ioannidou, "Special Education and ICTs.," International Journal of Emerging Technologies in Learning, vol. 8, no. 2, pp. 41-47, 2013.

[8] A. Drigas and R.-E. Ioannidou, "ICTs in Special Education: A Review," Communications in Computer and Information Science, vol. 278, pp. 357-364, 2013. https://doi.org/10.10 $\underline{07 / 978-3-642-35879-1 \quad 43}$

[9] L. Harasim, "Shift happens Online education as a new paradigm in learning," vol. 3, pp. 41-61, 2000.

[10] E. Demertzi, N. Voukelatos, Y. Papagerasimou, and A. S. Drigas, "Online Learning Facilities to Support Coding and Robotics Courses for Youth," International Journal of Engineering Pedagogy (iJEP), vol. 8, no. 3, p. 69, 2018. https://doi.org/10.3991/ijep.v8i3.8044

[11] J. Choi and A. Walters, "Exploring the Impact of Small-group Synchronous Discourse Sessions in Online Math Learning," Online Learning, vol. 22, no. 4, pp. 47-64, 2018. https://doi.org/10.24059/olj.v22i4.1511

[12] J. Choi, A. Walters, and P. Hoge, "Self-Reflection and Math Performance in an Online Learning Environment," Online Learning, vol. 21, no. 4, pp. 79-102, 2017. https://doi.org/ 10.24059/olj.v21i4.1249

[13] C. Hong et al., "The nature and level of learner-learner interaction in a chemistry massive open online course (MOOC)," Journal of Computing in Higher Education, vol. 29, no. 3, pp. 411-431, 2017. https://doi.org/10.1007/s12528-017-9135-3

[14] A. C. Robinson, J. Kerski, E. C. Long, H. Luo, D. DiBiase, and A. Lee, "Maps and the geospatial revolution: teaching a massive open online course (MOOC) in geography," Journal of Geography in Higher Education, vol. 39, no. 1, pp. 65-82, 2015. https://doi.org/10. $\underline{1080 / 03098265.2014 .996850}$

[15] D. Rennar-Potacco and A. Orellana, "Academically Supporting STEM Students From a Distance Through Videoconferencing: Lessons Learned," American Journal of Distance Education, vol. 32, no. 2, pp. 131-149, Apr. 2018. https://doi.org/10.1080/08923647. $\underline{2018.1446121}$

[16] D. Sun and C. K. Looi, "Designing a Web-Based Science Learning Environment for Model-Based Collaborative Inquiry," Journal of Science Education and Technology, vol. 22, no. 1, pp. 73-89, 2013. https://doi.org/10.1007/s10956-012-9377-9

[17] J. B. Silva, J. P. S. Simão, M. A. S. Cristiano, P. C. Nicolete, C. Heck, and K. S. Coelho, "A DC electric panel remote lab," International Journal of Online Engineering, vol. 12, no. 4, pp. 30-32, 2016. https://doi.org/10.3991/ijoe.v12i04.5096 
[18] M. Darrah, R. Humbert, J. Finstein, M. Simon, and J. Hopkins, "Are Virtual Labs as Effective as Hands-on Labs for Undergraduate Physics? A Comparative Study at Two Major Universities," Journal of Science Education and Technology, vol. 23, no. 6, pp. 803-814, 2014. https://doi.org/10.1007/s10956-014-9513-9

[19] C. Viegas et al., "Impact of a remote lab on teaching practices and student learning," Computers and Education, vol. 126, no. April, pp. 201-216, 2018.

[20] M. Robinson Jiménez, O. F. Avilés S., and M. F. Mauledoux M., "Remote lab for robotics applications," International Journal of Online Engineering, vol. 14, no. 1, pp. 187-194, 2018.

[21] A. Vijayan, C. Nutakki, D. Kumar, K. Achuthan, B. Nair, and S. Diwakar, "Enabling a freely accessible open source remotely controlled robotic articulator with a neuro-Inspired control algorithm," International Journal of Online Engineering, vol. 13, no. 1, pp. 61-75, 2017. https://doi.org/10.3991/ijoe.v13i01.6288

[22] A. Gokhale et al., "Cloud-hosted simulation-as-a-service for high school STEM education," Simulation Modelling Practice and Theory, vol. 58, no. 2015, pp. 255-273, 2015. https://doi.org/10.1016/j.simpat.2015.06.006

[23] K.-Y. Lin, K.-C. Yu, H.-S. Hsiao, Y.-H. Chu, Y.-S. Chang, and Y.-H. Chien, "Design of an assessment system for collaborative problem solving in STEM education," Journal of Computers in Education, vol. 2, no. 3, pp. 301-322, 2015. https://doi.org/10.1007/s40692015-0038-x

[24] P.-C. Lin, H.-T. Hou, S.-Y. Wu, and K.-E. Chang, "Exploring college students' cognitive processing patterns during a collaborative problem-solving teaching activity integrating Facebook discussion and simulation tools," The Internet and Higher Education, vol. 22, pp. 51-56, Jul. 2014. https://doi.org/10.1016/j.iheduc.2014.05.001

[25] T. Kobayashi, Y. Fukumura, A. Dharmawansa, N. Ogawa, H. Kanematsu, and D. M. Barry, "Virtual STEM Class for Nuclear Safety Education in Metaverse," Procedia Computer Science, vol. 35, pp. 1255-1261, 2014. https://doi.org/10.1016/j.procs.2014.08.224

[26] P. Segeč, M. Kubina, and P. Palúch, "ViRo - The Online Tool for the Networking Education," Procedia - Social and Behavioral Sciences, vol. 174, no. March, pp. 3788-3796, 2015. https://doi.org/10.1016/j.sbspro.2015.01.1114

[27] W. Ng, "A partnership-designed online module on climate science: Impact on year 10 teachers and students," Eurasia Journal of Mathematics, Science and Technology Education, vol. 15, no. 2, 2019. https://doi.org/10.29333/ejmste/100638

[28] C. M. Clevenger, M. Abdallah, W. Wu, and M. Barrows, "Assessing an Online Tool to Promote Sustainability Competencies in Construction Engineering Education," Journal of Professional Issues in Engineering Education and Practice, vol. 145, no. 1, p. 04018014 , 2018. https://doi.org/10.1061/(asce)ei.1943-5541.0000397

[29] M. Hostovecky, M. Misut, and K. Pribilova, "Web based testing in science education," in Innovations and Advances in Computing, Informatics, Systems Sciences, Networking and Engineering, Springer, 2015, pp. 247-254. https://doi.org/10.1007/978-3-319-06773-5_33

[30] K. Fellnhofer, "All-in-one: impact study of an online math game for educational purposes," International Journal of Technology Enhanced Learning, vol. 8, no. 1, pp. 59-76, 2016. https://doi.org/10.1504/ijtel.2016.075953

[31] P. Jagoda et al., "Alternate Reality Games as an Informal Learning Tool for Generating STEM Engagement among Underrepresented Youth: a Qualitative Evaluation of the Source," Journal of Science Education and Technology, vol. 26, no. 3, pp. 295-308, 2017. https://doi.org/10.1007/s10956-016-9679-4 
[32] A. Mavridis, A. Katmada, and T. Tsiatsos, "Impact of online flexible games on students' attitude towards mathematics," Educational Technology Research and Development, vol. 65, no. 6, pp. 1451-1470, 2017. https://doi.org/10.1007/s11423-017-9522-5

[33] C. Hursen and C. Bas, "Use of Gamification Applications in Science Education," International Journal of Emerging Technologies in Learning (iJET), vol. 14, p. 4, Jan. 2019.

\section{Authors}

C. Kefalis is with N.C.S.R. "Demokritos", Institute of Informatics and Telecommunications - Net Media Lab \& Mind-Brain R\&D, AgiaParaskevi15310,Athens, Greece.

A.Drigas is with N.C.S.R. 'Demokritos', Institute of Informatics and Telecommunications, and Coordinator of Net Media Lab \& Brain-Mind R\&D, Agia Paraskevi, 153 10, Athens, Greece (e-mail:dr@iit.demokritos.gr).

Article submitted 2019-04-18. Resubmitted 2019-07-09. Final acceptance 2019-07-03. Final version published as submitted by the authors. 